OPEN ACCESS

Edited by:

Mathieu Gruet,

Université de Toulon, France

Reviewed by:

Robin Souron

Université Claude Bernard

Lyon 1, France

Ren-Jay Shei,

Mallinckrodt, United States

*Correspondence:

Tingran Zhang

2878041101@qq.com

Jiong Luo

784682301@qq.com

Specialty section:

This article was submitted to

Integrative Physiology,

a section of the journal

Frontiers in Physiology

Received: 22 March 2021

Accepted: 23 June 2021

Published: 10 September 2021

Citation:

Wang $K$, Jiang $H$, Zhang $T$, Yin L, Chen $X$ and Luo J (2021) Comparison of Methods for the Estimation of the

Maximum Oxygen Uptake of Men

Drug Addicts.

Front. Physiol. 12:683942.

doi: 10.3389/fphys.2021.683942

\section{Comparison of Methods for the Estimation of the Maximum Oxygen Uptake of Men Drug Addicts}

\author{
Kun Wang ${ }^{1}$, Haonan Jiang ${ }^{1}$, Tingran Zhang ${ }^{1 *}$, Lian Yin ${ }^{1}$, Xi Chen $^{2}$ and Jiong Luo ${ }^{1 *}$ \\ 1 Research Centre for Exercise Detoxification, College of Physical Education, Southwest University, Chongqing, China, \\ ${ }^{2}$ Chongqing Drug Rehabilitation Administration, Chongqing, China
}

Background: Maximum oxygen uptake $\left(\mathrm{VO}_{2 \max }\right)$ is an important respiratory physiological index of the aerobic endurance of the body, especially for special groups such as drug addicts, and it is an important indicator for assessing the cardiopulmonary function and formulating exercise prescriptions. Although the cardiopulmonary exercise test (CPX) is a classic method to directly measure $\mathrm{VO}_{2 \max }$, this method is limited by factors such as cumbersome operating procedures and expensive equipment, resulting in its relatively low applicability. Recently, many studies have begun to focus on the estimation of $\mathrm{VO}_{2 \max }$ in different groups of people, but few studies have focused on drug addicts.

Methods: Fifteen chemically synthesized drug addicts (such as amphetamines) and Fifteen plant-derived drug addicts (such as heroin) were recruited the Chongqing Compulsory Isolation and Drug Rehabilitation Center in China. First, the $\mathrm{VO}_{2 \max }$ of subjects was directly measured through the CPX. Second, after subjects were fully rested, they were required to complete the 30-s high-leg raise, 1,000-m walk, and 3min step experiment. Finally, SPSS 21.0 software was used to perform the correlation and linear regression analysis to verify the estimated effectiveness.

Results: (1) Regardless of chemically synthesized or natural plant-derived drug addicts, the years of drug use and walking time of $1,000 \mathrm{~m}$ were significantly negatively correlated with $\mathrm{VO}_{2 \max }$ (chemically synthesized: $P<0.01$ and natural plant-derived: $P<0.05$ ), the number of 30-s high-leg raises was a significantly positive correlation with $\mathrm{VO}_{2 \max }(P$ $<0.05$ and $P<0.01$ ), and the 3-min step index was significantly positively correlated with $\mathrm{VO}_{2 \max }(P<0.01$ and $P<0.01)$. (2) Regression analysis shows that the 30-s high-leg lift, 1,000-m walking, and 3-min step experiment could effectively estimate the $\mathrm{VO}_{2 \max }$ of chemically synthesized and natural plant-derived drug addicts. (3) Multiple linear regression constructed by the years of drug use combined with the step index has the highest estimated accuracy for the $\mathrm{VO}_{2 \max }$ of chemically synthesized drug addicts (96.48\%), while the unary regression equation established by a single step index has the highest prediction accuracy for the $\mathrm{VO}_{2 \max }$ of natural plant-derived addicts (94.30\%).

Conclusion: The indirect measurement method could effectively estimate the $\mathrm{VO}_{2 \max }$ of drug addicts, but different measurement methods have certain differences in the 
estimation accuracy of $\mathrm{VO}_{2 \max }$ of different drug addicts. In the future, the physical characteristics of drug users can be fully considered, combined with more cutting-edge science and technology, to make the estimation accuracy of $\mathrm{VO}_{2 \max }$ closer to the real level.

Keywords: men, drug addicts, maximum oxygen uptake, cardiopulmonary exercise test, indirect measurement method

\section{INTRODUCTION}

Drug abuse (i.e., illegal substances) is a global problem that threatens public health and undermines social productivity. In China, at the end of 2018, there were 2.404 million drug users, accounting for $0.18 \%$ of the total population of the country (National Anti-Drug Committee Office, 2019). Although the growth rate has reduced, the total population of drug abusers was still huge. Drug abuse will cause serious damage to the psychological and physiological health of drug users. For example, the long-term drug use behavior was considered not only to cause loss of appetite, weakness of spirit, and dysfunction in brain regions such as forehead leaves and almond nucleus, but also led to different degrees of influence of respiratory, cardiovascular, and immune systems (Li, 2001; Huang et al., 2010; Ozburn et al., 2015; Zarrabi et al., 2016). In addition, according to the composition and harm of drugs, amphetamine-based chemically compounds are usually called chemically synthesized drugs, while heroin-based plant extracts are called natural plant-derived drugs (Xue, 2010; Feng et al., 2019). There are certain differences in the damage of different types of drugs to individuals. The chemically synthesized drugs mainly damage the central nervous system, and they easily cause mental damage and cognitive impairment (Panenka et al., 2013), while natural plantderived drugs mainly damage the immune function and easily damage the heart and lungs or other internal organs $(\mathrm{Hu}, 1992$; Ye, 1995). However, previous studies tend to focus on the mental (Stogner et al., 2014; Wang et al., 2019) and brain health (van Holst and Schilt, 2011; Chen S. J. et al., 2017) of drug abusers, and there were relatively few studies on the cardiopulmonary fitness of different drug addicts.

Maximum oxygen uptake $\left(\mathrm{VO}_{2 \max }\right)$ refers to the amount of oxygen that the human body could take in per kilogram of body weight in 1 min during maximum or exhausting exercise. It was an important indicator for assessing individual aerobic endurance and cardiopulmonary function (Katzmarzyk et al., 2004) and also a crucial indicator for formulating aerobic exercise prescriptions for special groups such as drug addicts. After the American Heart Association listed cardiorespiratory endurance as the "fifth most important" vital sign in 2016, the importance of $\mathrm{VO}_{2 \max }$ has received further attention (Coquart et al., 2016). The classic method of evaluating and measuring $\mathrm{VO}_{2 \max }$ was to directly collect the breathing gas of the subject during exhausting exercise through a cardiopulmonary exercise test (CPX) and then calculate the $\mathrm{VO}_{2 \max }$ by the cardiopulmonary function test system. The data measured by CPX have high credibility and were considered as the "gold standard" for measuring $\mathrm{VO}_{2 \max }$, but it also has disadvantages such as expensive instruments, difficulty to carry, cumbersome operating procedures, and high requirements for the test environment, and there were potential safety risks for special people such as the old, the weak, the sick, and the young (Liu and Dong, 2013; Dong et al., 2017). For the compulsory drug addicts, it was quite difficult to directly measure the $\mathrm{VO}_{2 \max }$ of them due to their particularities, environment, equipment, and other internal and external factors. However, the effective assessment and measurement of $\mathrm{VO}_{2 \max }$ levels of drug addicts were crucial for formulating personalized and effective exercise prescriptions and improving the cardiopulmonary function of drug addicts.

The indirect measurement method refers to the conversion of the measured value into many directly measurable quantities, and the measurement results were calculated by the mathematical formulae. At present, there were many indirect measurement methods for $\mathrm{VO}_{2 \max }$, and the common indirect measurement methods include 20-m turn back run (Han, 2010; Paradisis et al., 2014), Cooper's 12-min run test (CRT) (Cooper, 1968), 6-min walk test (Ross et al., 2010), 6-min stair climbing (Guo et al., 2016), 12-min walk test (Kittredge et al., 1994), 1,000-m run (Li et al., 2010), and step test (Guo et al., 2005). Some studies use CRT to estimate the cardiopulmonary function of special groups such as asthma and obese children (Calders et al., 2008; Weisgerber et al., 2009). Meanwhile, studies have suggested that some indirect measurement methods have certain disadvantages. For example, the 20-m reentry run and CRT have a large load, the exercise load of the latter was more difficult to control (Dong et al., 2017), and the 6-min upstairs and downstairs have a moderate load but were prone to falls. In contrast, the step test has become a common indirect measurement method of $\mathrm{VO}_{2 \max }$ due to its low requirements for equipment and test sites (Dong et al., 2017; Fan et al., 2019). Meanwhile, the 30-s high-leg raise test was similar to the step test, which was suitable for largesample group testing and was convenient for promotion. The load of 1,000-m walking was moderate, the operation method was simple, and the safety factor was high (Dong et al., 2017). Based on this, we speculated that the above three indirect measurement methods may have more application potential in estimating the $\mathrm{VO}_{2 \max }$ of drug addicts, and we have previously verified the effectiveness of the step test in predicting the $\mathrm{VO}_{2 \max }$ of women methamphetamine addicts (Wang et al., 2020). However, the cardiorespiratory endurance of body will have gender differences to a large extent, and it was currently unknown which method was more effective in estimating the $\mathrm{VO}_{2 \max }$ of men drug addicts.

In addition, from the perspective of drug users, the type of drug use and the years of drug use seem to be the two important study variables (Chen Y. L. et al., 2017; Wang et al., 2019). Therefore, based on the previous study, this study adopted the 
TABLE 1 | The demographic characteristics of subjects.

\begin{tabular}{lccc}
\hline Items & $\begin{array}{c}\text { Chemically } \\
\text { synthesized } \\
\text { drug addicts } \\
(\boldsymbol{n}=\mathbf{1 5})\end{array}$ & $\begin{array}{c}\text { Natural plant-derived } \\
\text { drug addicts } \\
(\boldsymbol{n}=\mathbf{1 5})\end{array}$ & $\boldsymbol{P}$ \\
\hline Age (years) & $28.13 \pm 4.93$ & $36.67 \pm 4.12$ & $<0.001$ \\
Height (m) & $1.66 \pm 0.99$ & $1.67 \pm 0.54$ & 0.829 \\
Weight (kg) & $68.31 \pm 11.37$ & $64.81 \pm 7.95$ & 0.337 \\
BMl & $24.68 \pm 2.63$ & $23.39 \pm 2.56$ & 0.186 \\
Years of drug use (year) & $4.27 \pm 1.58$ & $6.80 \pm 2.21$ & 0.001 \\
Resting heart rate (beats) & $78.60 \pm 7.60$ & $77.53 \pm 6.63$ & 0.685 \\
\hline
\end{tabular}

"Chemically synthesized drug" mainly refers to methamphetamine, ecstasy, and other amphetamine chemically synthesized drugs, and "natural plant-derived drug" mainly refers to drugs extracted from natural plants such as heroin, morphine, and cannabis (Xue, 2010).

comparative analysis of 2 (chemically synthesized and natural plant-derived drug addicts) $\times 3$ (30-s leg elevation, $1,000 \mathrm{~m}$ walking, and step test) to find out the most suitable indirect measurement method of $\mathrm{VO}_{2 \max }$ for men drug addicts of different types of drug addicts and provide a theoretical and practical reference for the future development of the exercise rehabilitation prescriptions.

\section{MATERIALS AND METHODS}

\section{Subjects}

A total of 38 men drug addicts were recruited voluntarily in the Xiyanping Education, Correction and Addiction Treatment Center in Chongqing, China. A total of 30 people were finally determined to participate in the trial through the following inclusion and exclusion criteria: (1) between 18 and 50 years old, (2) currently in a state of imprisonment and has undergone compulsory withdrawal rehabilitation for more than 3 months, (3) education level was elementary school and above, (4) diagnosis through structured interviews meets the DSM-IV evaluation criteria for drug-dependent persons, (5) no history of mental illness or any immediate family members suffering from mental illness, (6) no heart or cardiovascular disease, and (7) no physical disability or no aerobic exercise of moderateintensity or above. In terms of demographic characteristics, the age $(P<0.001)$ and the years of drug use $(P<0.01)$ of natural plant-derived drug addicts were significantly higher than those of chemically synthesized drug addicts, and there was no significant difference in height, weight, BMI, and resting heart rate between the two $(P>0.05)$. See Table 1 for details.

\section{Research Procedure}

All the 30 subjects who were screened and included in the trial signed the informed consent form after they were aware of the content and requirements of this study. Then, they completed the five sequence tasks, namely baseline test, 30-s high-leg lift, 1,000m walk, 3-min step test, and CPX (except for the baseline test and CPX, the other three tests were in random order), with more than $24 \mathrm{~h}$ between each task test. It should be pointed out that since the CPX requires the subject to pedal to the exhausted state, the subject should rest for more than $72 \mathrm{~h}$ before performing the test. All experimental tasks are scheduled to be conducted from 9:00 a.m. to 11:30 a.m. or 2:00 p.m. to 4:00 p.m. every day.

1) Baseline test. Background information, such as demographic data, drug use history, drug dependence survey, and physical fitness indicators in a quiet state, such as blood pressure, height, and weight.

2) Thirty-second high-leg lift. When raising the legs on the spot, the subjects were required to look straight ahead with both eyes, keep the upper body straight, alternately raise the legs to level, with the thighs and the abdomen at a $90^{\circ}$ angle, and swing the arms naturally in a running posture. During the experiment, subjects need to raise their legs in situ for the $30 \mathrm{~s}$ at the fastest speed. The time was controlled by a recorder with a stopwatch, and another recorder was responsible for recording the number of the subjects who raised their legs in $30 \mathrm{~s}$ (i.e., lifting of the left or right leg was considered to be completed once). Finally, the total number of leg lifts was used as a reference index for estimating $\mathrm{VO}_{2 \max }$.

3) 1,000-m walk. The subjects were required to swing their arms vigorously in strides and quickly walk $1,000 \mathrm{~m}$ on the outdoor track and field, and they were not allowed to rest or walk slowly in the task. Throughout the test, the tester used a stopwatch to record the time it took for the subject to effectively complete the $1,000 \mathrm{~m}$. Finally, the total time consumed (seconds) was used as a reference index for estimating $\mathrm{VO}_{2 \text { max }}$.

4) 3-min step test. The subjects continued to go up/down a 40$\mathrm{cm}$ step at a fixed speed of 30 times/min (one up and down is one time) within $3 \mathrm{~min}$, and in the process of climbing the steps, a metronome was used to give the auditory feedback for the subjects to control the pedaling rhythm. As soon as the 3-min step-up was completed, the subject immediately sat on the stool to get relaxed and adjusted his/her breathing, and a step tester was used to measure the heart rates of the subject thrice during the recovery period. After the data collection was completed, the step test was ended. It should be pointed out that if the stepping rhythm is slow for three consecutive beats during the step test, the stepping test will be stopped immediately.

5) Cardiopulmonary exercise test. After the subjects put on the test equipment, they sat upright on a stationary power bicycle. The load plan was as follows: the first 2 min were no-load exercise $(0 \mathrm{w})$, then the exercise load is linearly increased by $10 \mathrm{w} / \mathrm{min}$, and the subject needs to maintain the speed of $6070 \mathrm{r} / \mathrm{min}$ to pedal the power bicycle. During this period, if the pedaling rhythm was $<60 \mathrm{r} / \mathrm{min}$ for $3 \mathrm{~s}$, stop pedaling immediately. During the test, the equipment system will synchronously and continuously record the gas metabolism parameters of the subject, such as $\mathrm{VO}_{2}$, at each moment, and the subject will continue to be verbally motivated throughout the process until reaching a state of exhaustion [i.e., in line with the stop motion conditions of American College of Sports Medicine (ACSM, 2013)]. During the entire pedaling process, testers will be there to provide safety protection and supervision to prevent falling. 
It is noted that in the above five tests, if the subject does not complete or completes any of the tests as required, then all the test data of the subject will not be included in the final statistical analysis. Meanwhile, in this study, based on the recommendations of the ACSM, the test should be stopped when the subject has the following symptoms during the test: (1) the subject voluntarily asks to stop exercising, (2) the subject has symptoms such as dizziness, nausea, pale face, difficulty in breathing, and weakness in limbs, (3) abnormal heart rate, such as too fast or too slow, and (4) $\mathrm{VO}_{2}$ reaches the plateau (i.e., a $\mathrm{VO}_{2}$ growth rate was $<150 \mathrm{ml} / \mathrm{min}$ ). The heart rate of the subject during exercise was monitored by the SUUNTO Smart Sensor Bluetooth heart rate belt. This study has been approved by the Ethics Review Committee of Southwest University Hospital in China (No. 201905).

\section{Measuring Tools \\ Power Bike}

The stationary power bicycle (Lode-906900) made in the Netherlands was used for pedaling. The subjects could adjust the height of the seat by themselves, and control the speed of the power car by pedaling rhythm. The heart rate belt was connected via Bluetooth on the power car screen, which will display the changes in the real-time heart rate of the subject.

\section{Portable Cardiopulmonary Function Telemeter}

A portable cardiopulmonary function telemeter (PKSP-11, China) made in China was used to monitor the respiratory indicators of subjects, such as $\mathrm{VO}_{2 \max }$, and the subject needs to wear a mask and a gas analyzer. Before each test, the equipment was calibrated with standard gases (i.e., 15\% oxygen, $5 \%$ carbon dioxide, and $80 \%$ nitrogen) and with a special capacity calibration cylinder (Cortex-11, Germany). The changes in the cardiopulmonary function indicators of the subject during exercise were simultaneously monitored, and the gas exchange of the subject during the entire exercise process was collected.

\section{Step Tester}

The China-made TZCS-3 step tester was used to measure the step index, and the heart rate was tested by infrared detection of the blood flow changes of the finger pulse, which was convenient to use and high in accuracy. The subject sits on the chair in a relaxed posture and puts the middle finger into the finger pulse test clip with the palm down. After a few seconds, the indicator light on the finger pulse clip will start flashing according to the pulse. For a total of three tests, each lasting for $30 \mathrm{~s}$ (with an interval of $30 \mathrm{~s}$ ), the flashing of the signal light was synchronized with the heartbeat of the subject, and the heart rate and step index of the recovery period were automatically generated after $3.5 \mathrm{~min}$.

\section{Other}

In addition, there was a portable step $(40 \mathrm{~cm}$, China), electronic blood pressure meter (RS800CX, Finland), stopwatch (ZSD-013, Xingluda, China), and other small test tools.

\section{Statistical Analysis}

The SPSS 21.0 statistical software was used to process and analyze the data. First, the independent sample $t$-test was used to test the
TABLE 2 | Statistics of test data of subjects ( $n=30$, mean \pm SD).

\begin{tabular}{lcccc}
\hline Items & $\begin{array}{c}\text { Chemically } \\
\text { synthesized } \\
(\boldsymbol{n}=\mathbf{1 5})\end{array}$ & $\begin{array}{c}\text { Natural } \\
\text { plant-derived } \\
(\boldsymbol{n}=\mathbf{1 5})\end{array}$ & $\boldsymbol{t}$ & $\boldsymbol{P}$ \\
\hline Years of drug use (year) & $4.27 \pm 1.58$ & $6.80 \pm 2.21$ & -3.61 & 0.001 \\
VO $_{2 \text { max }}$ (ml/min/kg) & $30.73 \pm 2.31$ & $27.40 \pm 3.36$ & 3.17 & 0.004 \\
30 s high leg raises (frequency) & $85.13 \pm 7.06$ & $79.00 \pm 6.35$ & 2.50 & 0.018 \\
1000 m walking time (min) & $9.01 \pm 0.57$ & $9.74 \pm 0.75$ & -3.00 & 0.006 \\
3 min step index & $56.37 \pm 5.28$ & $48.54 \pm 8.07$ & 3.14 & 0.004
\end{tabular}

"VO $\mathrm{O}_{2 \text { max }}$ "refers to the true maximal oxygen uptake value obtained through the CPX.

index differences between different types of drug addicts. Second, the Pearson's correlation analysis was used to test the correlation between the variables, and then linear regression analysis was used to test the estimated effect power. Finally, the Bland Altman chart was used to test the level of agreement between the estimated value and the true value. After the Shapiro-Wilk test, all the data were collected using the normal distribution $(P>$ $0.05)$, and the parameter significance level was set to $\alpha=0.05$.

\section{RESULTS}

\section{The Difference Analysis of the Test Results of Different Drug Addicts}

Table 2 shows that the different types of drug addicts have significant differences in many test indicators. Among them, the years of drug addicts and the walking time of $1,000 \mathrm{~m}$ of natural plant-derived drug addicts were significantly higher than those of chemically synthesized drug addicts $(t=-3.61, P=0.001$ and $t=-3.00, P=0.006$, respectively). The $\mathrm{VO}_{2 \max }, 30$-s highleg raises, and 3-min step index of chemically synthesized drug addicts were significantly higher than those of natural plantderived drug addicts $(t=3.17, P=0.004 ; t=2.50, P=0.018$; and $t=3.14, P=0.004$, respectively).

\section{Correlation Analysis Between $\mathrm{VO}_{2 \max }$ Predictive Indicators and Measured Indicators}

Among chemically synthesized drug addicts (Table 3), the $\mathrm{VO}_{2 \max }$ was significantly negatively correlated with the years of drug use and walking time $(r=-0.66, P=0.007 ; r=-0.64, P=$ 0.009 , respectively), while the $\mathrm{VO}_{2}$ max was significantly positively correlated with the number of high-leg raises and the step index ( $r=0.55, P=0.034 ; r=0.74, P=0.002$, respectively). Among natural plant-derived drug addicts (Table 4), the $\mathrm{VO}_{2 \max }$ was significantly negatively correlated with the years of drug use and the walking time $(r=-0.63, P=0.011 ; r=-0.61, P=$ 0.016 , respectively), while the $\mathrm{VO}_{2 \max }$ was significantly positively correlated with the number of high-leg raises and the step index ( $r=0.64, P=0.009 ; r=0.77, P=0.001$, respectively). The correlation among the main variables was significant, which provides a theoretical basis for the subsequent regression analysis (see Table 3 for details). 
TABLE 3 | Correlation matrix of chemically synthesized drug addicts $(n=30)$.

\begin{tabular}{|c|c|c|c|c|c|}
\hline & $\begin{array}{l}\text { Years of } \\
\text { drug use }\end{array}$ & $\mathrm{VO}_{2 \max }$ & $\begin{array}{l}\text { High leg } \\
\text { raises }\end{array}$ & $\begin{array}{c}\text { Walking } \\
\text { time }\end{array}$ & $\begin{array}{l}\text { Step } \\
\text { index }\end{array}$ \\
\hline Years of drug use & 1 & & & & \\
\hline $\mathrm{VO}_{2 \max }$ & $-0.66^{\star \star}$ & 1 & & & \\
\hline High leg raises & -0.46 & $0.55^{\star}$ & 1 & & \\
\hline Walking time & $0.64^{\star \star}$ & $-0.64^{\star \star}$ & $-0.59^{*}$ & 1 & \\
\hline Step index & $-0.53^{\star}$ & $0.74^{\star \star}$ & $0.52^{\star}$ & -0.43 & 1 \\
\hline Mean & 4.27 & 30.73 & 85.13 & 9.01 & 56.37 \\
\hline SD & 1.58 & 2.31 & 7.06 & 0.57 & 5.28 \\
\hline
\end{tabular}

${ }^{*} P<0.05,{ }^{* *} P<0.01$.

TABLE 4 | Correlation matrix of natural plant-derived drug addicts $(n=30)$.

\begin{tabular}{lccccc}
\hline & $\begin{array}{c}\text { Years of } \\
\text { drug use }\end{array}$ & $\mathbf{V O}_{2 \text { max }}$ & $\begin{array}{c}\text { High leg } \\
\text { raises }\end{array}$ & $\begin{array}{c}\text { Walking } \\
\text { time }\end{array}$ & $\begin{array}{c}\text { Step } \\
\text { index }\end{array}$ \\
\hline Years of drug use & 1 & & & & \\
$\mathrm{VO}_{2 \text { max }}$ & $-0.63^{\star}$ & 1 & & & \\
High leg raises & -0.31 & $0.64^{\star \star}$ & 1 & & \\
Walking time & $0.59^{*}$ & $-0.61^{\star}$ & $-0.59^{*}$ & 1 & \\
Step index & $-0.52^{\star}$ & $0.77^{\star *}$ & 0.42 & $-0.64^{\star *}$ & 1 \\
Mean & 6.80 & 27.40 & 79.00 & 9.73 & 48.54 \\
$S D$ & 2.21 & 3.36 & 6.35 & 0.75 & 8.07 \\
\hline
\end{tabular}

${ }^{*} P<0.05,{ }^{* *} P<0.01$.

\section{Linear Regression Analysis of Different Methods for Estimating $\mathrm{VO}_{2 \max }$ of Drug Addicts \\ Unary Linear Regression Analysis}

In this study, the real measurement of the $\mathrm{VO}_{2 \max }$ was used as the dependent variable, and the independent variables were the 30$\mathrm{s}$ high-leg raises, the 1,000-m walking time, and the 3-min step index to establish a linear regression equation.

Among chemically synthesized drug addicts, the 30-s high-leg lift could effectively predict the $\mathrm{VO}_{2 \max }\left(R=0.55, R^{2}=0.30, P=\right.$ 0.034 , Figure 1A), the 1,000 - $\mathrm{m}$ walking could effectively predict the $\mathrm{VO}_{2 \max }\left(R=0.64, R^{2}=0.41, P=0.009\right.$, Figure $\left.1 \mathrm{~B}\right)$, and the 3-min step test could also effectively predict the $\mathrm{VO}_{2 \max }(R=$ $0.74, R^{2}=0.55, P=0.002$, Figure $1 C$ ). From the results, the three methods could effectively estimate the $\mathrm{VO}_{2 \max }$ of chemically synthesized drug addicts to varying degrees. Among them, the determination coefficient $R^{2}$ of 3-min stepping was the highest, indicating that the 3-min step test has the best predictive effect.

Among natural plant-derived drug addicts, the 30-s high-leg lift could effectively predict the $\mathrm{VO}_{2 \max }\left(R=0.64, R^{2}=0.42, P=\right.$ 0.009 , Figure $2 \mathrm{~A}$ ), the 1,000 - $\mathrm{m}$ walking could effectively predict the $\mathrm{VO}_{2 \max }\left(R=0.61, R^{2}=0.37, P=0.016\right.$, Figure $\left.2 \mathrm{~B}\right)$, and the 3-min step test could also effectively predict the $\mathrm{VO}_{2 \max }(R$ $=0.77, R^{2}=0.59, P=0.001$, Figure 2C). From the results, the three methods could effectively estimate the $\mathrm{VO}_{2 \max }$ of natural plant-derived drug addicts to varying degrees. Among them, the determination coefficient $R^{2}$ of 3-min stepping was the highest, indicating that the 3 -min step test has the best predictive effect.

\section{Multiple Linear Regression Analysis}

This study combined the years of drug use to explore more in-depth methods of estimating the $\mathrm{VO}_{2 \max }$ of drug addicts (Table 5). Among chemically synthesized drug addicts, the years of drug use could effectively estimate the $\mathrm{VO}_{2 \max }$ (Equation 1), and the regression equation was as follows: $y=-0.663 x+34.878$ ( $\left.R^{2}=0.44, P=0.007\right)$. On this basis, we added the number of high-leg lifts as an independent variable and found that the years of drug use combined with the number of high-leg lifts could not effectively estimate the $\mathrm{VO}_{2 \max }$ (Equation 2). Similarly, the years of drug use combined with walking time could not effectively estimate the $\mathrm{VO}_{2 \max }$ (Equation 3). However, this study found that the years of drug use $\left(x_{1}\right)$ combined with the step index $\left(x_{2}\right)$ could effectively estimate the $\mathrm{VO}_{2 \max }$ of men drug addicts (Equation 4), and the regression equation was as follows: $y=$ $-0.551 x_{1}+0.238 x_{2}+19.647\left(R^{2}=0.65, P=0.019\right)$. Among natural plant-derived drug addicts, the years of drug use could effectively estimate the $\mathrm{VO}_{2 \max }$ (Equation 5), and the regression equation was as follows: $y=-0.962 x+33.942\left(R^{2}=0.40, P=\right.$ 0.011 ). On this basis, we added the number of high-leg lifts as an independent variable and found that the years of drug use $\left(x_{1}\right)$ combined with the number of high-leg lifts $\left(x_{2}\right)$ could effectively estimate the $\mathrm{VO}_{2 \max }$ (Equation 6), and the regression equation was as follows: $y=-0.732 x_{1}+0.263 x_{2}+11.631\left(R^{2}=0.63\right.$, $P=0.020)$. The years of drug use combined with walking time could not effectively estimate the $\mathrm{VO}_{2 \max }$ (Equation 7). However, this study found that the years of drug use $\left(x_{1}\right)$ combined with the step index $\left(x_{3}\right)$ could effectively estimate the $\mathrm{VO}_{2 \max }$ of men drug addicts (Equation 8), and the regression equation was as follows: $y=-0.488 x_{1}+0.250 x_{3}+18.598\left(R^{2}=0.67, P=0.009\right)$.

\section{Reliability and Validity Analysis of Different Methods for Estimating $\mathrm{VO}_{2 \max }$ of Drug Addicts}

To clarify the effectiveness of different methods for estimating $\mathrm{VO}_{2 \max }$, we separately calculated the estimation accuracy of each available method (Table 6). The results showed that: (1) among the chemically synthesized drug addicts, whether it was a unary linear regression or multiple linear regression, the estimation accuracy of the step index was higher. In comparison, the $\mathrm{VO}_{2 \max }$ estimation accuracy of chemically synthesized drug addicts based on the years of drug use combined with the step index was higher (96.48\%). (2) Among natural plant-derived drug addicts, the estimation accuracy of the unary linear regression equation established by the step index was the highest (94.30\%), the years of drug use combined with the times of high-leg lifts and the years of drug use combined with the step index were second, and the estimation accuracy of both was $94.03 \%$.

To further verify the best estimation method of $\mathrm{VO}_{2 \max }$ for chemically synthesized and natural plant-derived drug addicts, in this study, the Bland Altman diagram was used to evaluate the reliability and validity of the estimation of the $\mathrm{VO}_{2 \max }$ of chemically synthesized drug addicts estimated by the years of drug use combined with the step index (Figure 3A) and the step index to estimate the $\mathrm{VO}_{2 \max }$ of natural plant-derived drug addicts (Figure 3B), respectively. The results showed that the two 

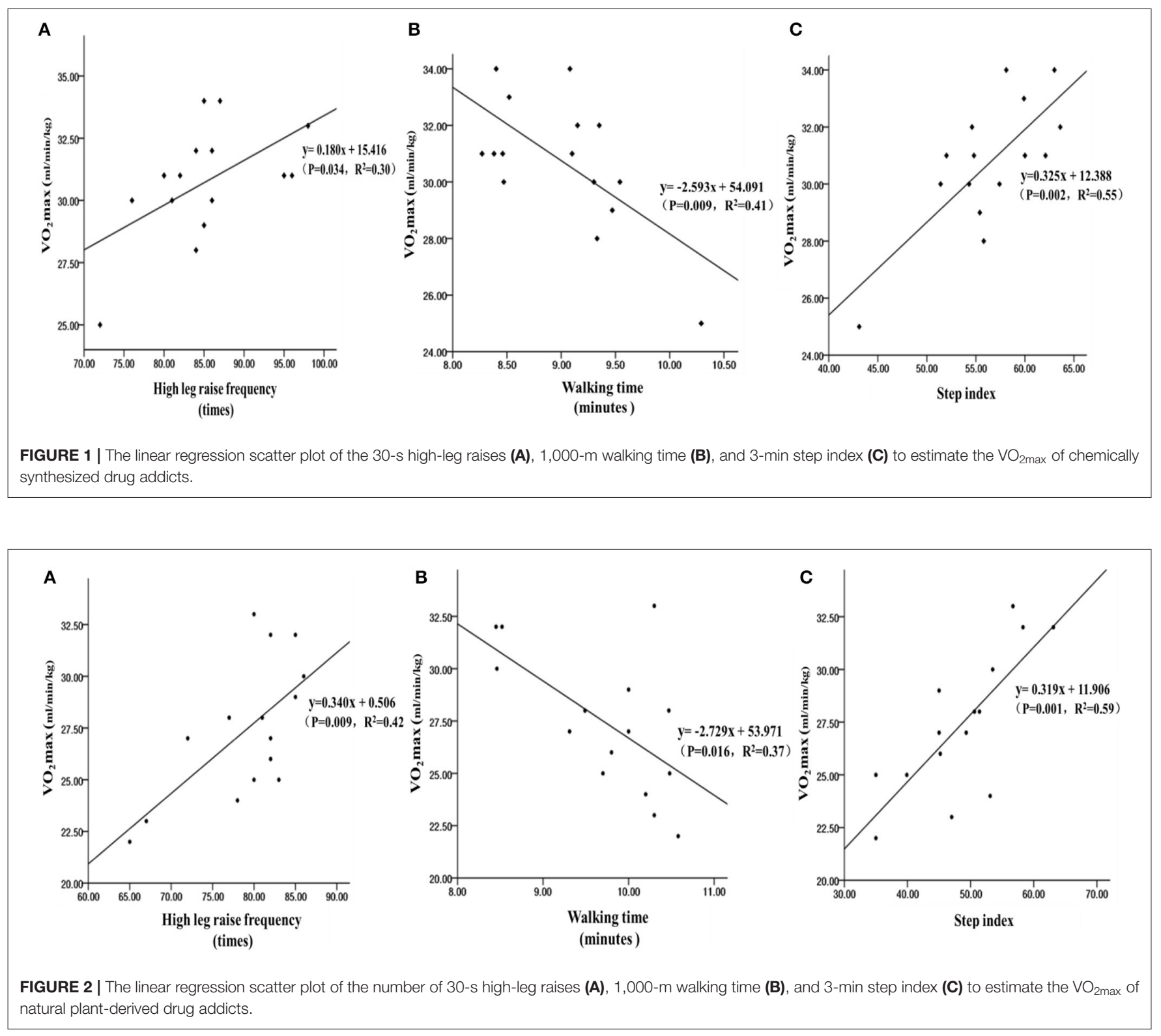

TABLE 5 | Stepwise regression of different methods to estimate $\mathrm{VO}_{2 \max }(n=30)$.

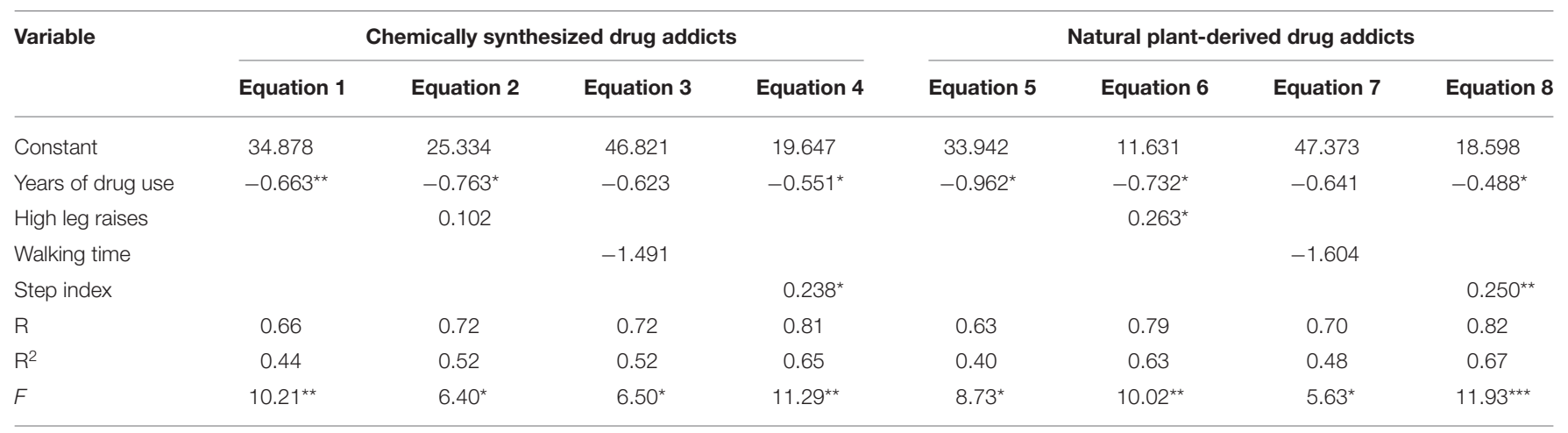

${ }^{*} P<0.05,{ }^{* *} P<0.01,{ }^{* * *} P<0.001$. The coefficients in the table were nonstandardized $\beta$ values. 
TABLE 6 | Accuracy statistics of different methods to estimate the $\mathrm{VO}_{2 \max }(n=30)$.

\begin{tabular}{|c|c|c|c|c|c|c|c|c|}
\hline & \multicolumn{4}{|c|}{ Chemically synthesized drug addicts } & \multicolumn{4}{|c|}{ Natural plant-derived drug addicts } \\
\hline & Regression equation & $R^{2}$ & $95 \% \mathrm{Cl}$ & Accuracy (\%) & Regression equation & $R^{2}$ & $95 \% \mathrm{Cl}$ & Accuracy (\%) \\
\hline A & $y=0.180 x+15.416$ & 0.30 & $(0.23,0.34)$ & 94.81 & $y=0.340 x+0.506$ & 0.42 & $(0.40,0.45)$ & 92.89 \\
\hline B & $y=-2.593 x+54.091$ & 0.41 & $(0.39,0.45)$ & 95.16 & $y=-2.729 x+53.971$ & 0.37 & $(0.34,0.41)$ & 92.79 \\
\hline C & $y=0.325 x+12.388$ & 0.55 & $(0.52,0.61)$ & 95.60 & $y=0.319 x+11.906$ & 0.59 & $(0.56,0.62)$ & 94.30 \\
\hline$A+D$ & - & - & - & - & $y=-0.732 x_{1}+0.263 x_{2}+11.631$ & 0.63 & $(0.61,0.66)$ & 94.03 \\
\hline $\mathrm{C}+\mathrm{D}$ & $y=-0.551 x_{1}+0.238 x_{2}+19.647$ & 0.65 & $(0.62,0.68)$ & 96.48 & $Y=-0.488 x_{1}+0.250 x_{2}+18.598$ & 0.67 & $(0.65,0.70)$ & 94.03 \\
\hline
\end{tabular}

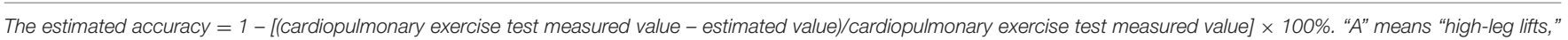
" $B$ " means "walking time," "C" means "step index," and " $D$ " means "years of drug use."

estimation methods have a good consistency. It was worth noting that the latter has a slight deviation, and we speculated that this may be related to the sample size. Studies have shown that when the sample size was small, the sampling error will be relatively large, and the larger the sample size, the wider the data coverage, the smaller the limits of agreement CI range, the easier it is to get a better consistent conclusion.

\section{DISCUSSION}

This study was the first to systematically explore the method of estimating the $\mathrm{VO}_{2 \max }$ of men drug addicts. We have fully considered the differences in drug use types and estimation methods, and through comparative analysis of different indirect measurement methods, we have, respectively, revealed the best estimation formulas for $\mathrm{VO}_{2 \max }$ of chemically synthesized and natural plant-derived drug addicts. This may provide convenience for the targeted monitoring of the cardiopulmonary function of men addicts of different drug types and then provide a basis and reference for formulating scientific and targeted exercise rehabilitation prescriptions.

We found that there were significant differences in the $\mathrm{VO}_{2 \max }$ of addicts of different types of drugs, and the $\mathrm{VO}_{2 \max }$ of chemically synthesized drug addicts was significantly higher than that of natural plant-derived drug addicts. Previous studies have shown that synthetic chemical drugs such as amphetamine, which mainly act on the central nervous system of the human body, were more likely to cause individual mental damage and cognitive impairment and have strong neurological dependence (Panenka et al., 2013; Wang and Zhu, 2017). Natural plantderived drug addicts such as marijuana and heroin were mainly involved in damaging the immune function of the body and were more likely to cause damage to the heart, liver, kidney, and other organs of the drug addicts (Hu, 1992; Ye, 1995; Zhu, 2000), and the long-term use of cocaine could lead to decreased lung function (Yang, 2006). It shows that different types of drugs have different degrees of damage to the body of drug users, which shows that the grouping of drug users according to the types of drug use has certain scientific rationality. Meanwhile, compared with synthetic chemical drugs, the natural plant-derived drug addicts were often older, and the latter has a higher number of years of drug use. It can be seen that the age and years of drug use may be two moderating variables for drug damage to the body, and it was manifested as the older and the longer the drug use, the lower the value of $\mathrm{VO}_{2 \max }$. However, previous studies have mainly focused on the difference in the years of drug use, for example, the degree of damage to the body caused by drug use will increase with the increase in the years of drug use (Jiang, 2006; Chen Y. L. et al., 2017). Therefore, the relationship between age and the cardiopulmonary function of drug addicts needs to be further studied. In addition, it should be noted that $\mathrm{VO}_{2 \max }$ plays an important role in assessing the cardiopulmonary function of drug addicts. The $\mathrm{VO}_{2 \max }$ was not only a risk indicator for estimating cardiovascular degradation and monitoring the functional status of the patient (Aspenes et al., 2011) but also an important indicator for assessing the aerobic endurance of the body (Bosquet et al., 2002), and cardiorespiratory endurance such as $\mathrm{VO}_{2 \max }$ was considered to have significant gender differences ( $\mathrm{Li}$ et al., 2007; Lin et al., 2018). The lower the level of cardiopulmonary function, the higher the risk of premature death, which maintaining a good cardiorespiratory fitness level can reduce the risk and mortality of many chronic diseases (Larsen et al., 2014). In the field of exercise detoxification, $\mathrm{VO}_{2 \max }$ was considered to be one of the important indicators to assess the physical fitness status of drug addicts and the effect of exercise intervention, and the $\mathrm{VO}_{2 \max }$ of drug addicts could be effectively improved through active exercise (Dolezal et al., 2013; Wang and Zhu, 2017), thereby reducing the risk of diseases such as heart disease and hypertension (Henry et al., 2012). Therefore, strengthening the monitoring of $\mathrm{VO}_{2 \max }$ of drug addicts (especially natural plant-derived drug addicts) was particularly important for ensuring their quality of life and formulating targeted rehabilitation training prescriptions.

The results of this study showed that the use of 30-s high-leg lift, 1,000-m walking, and 3-min stepping were all significantly correlated with the $\mathrm{VO}_{2 \max }$ of drug addicts, and the three methods could effectively estimate the $\mathrm{VO}_{2 \max }$ of drug addicts, which indicates that the indirect measurement method was equally effective for drug addicts, and could reflect the level of cardiorespiratory endurance of drug addicts to a certain extent, which was more consistent with previous studies (Li et al., 2010; Dong et al., 2017). Interestingly, we found through comparison that there were certain differences in the best estimation methods of $\mathrm{VO}_{2 \max }$ among different drug addicts. It was shown that multiple linear regression constructed with the years of drug use combined with the step index was more effective and accurate in 

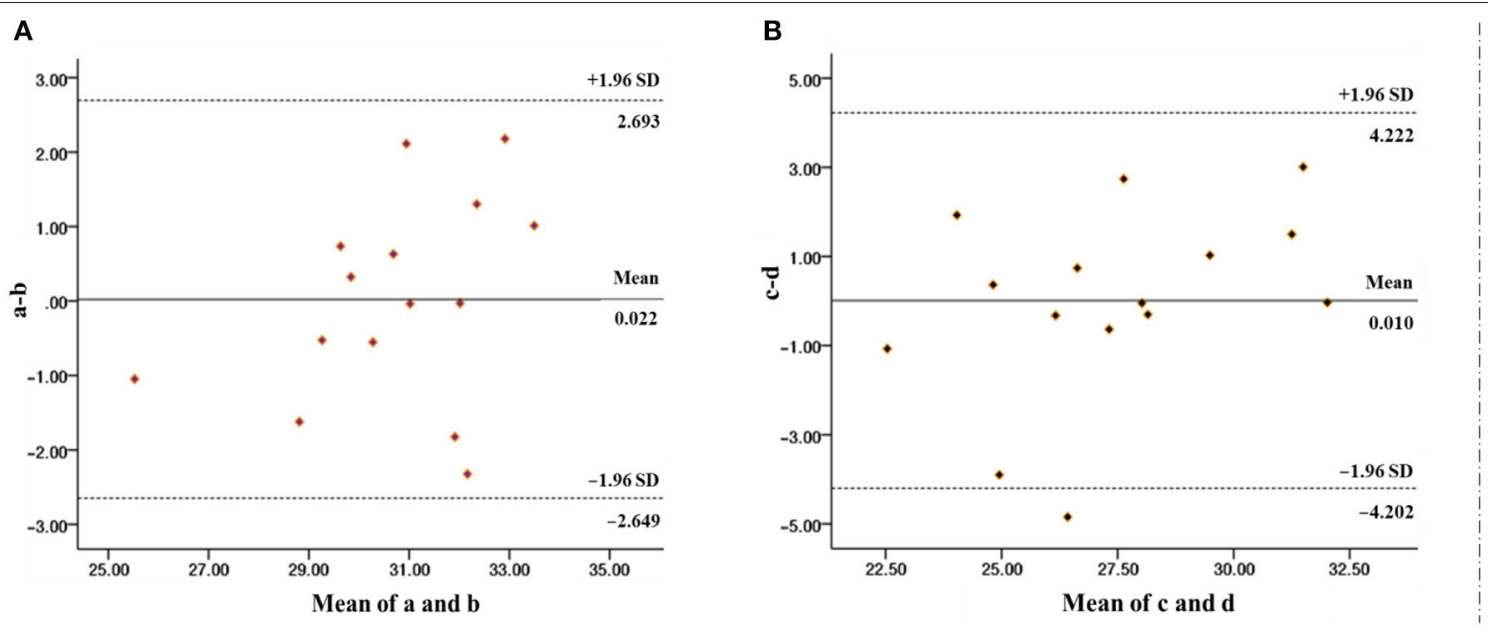

FIGURE 3 | Bland Altman diagrams of different methods for estimating the $\mathrm{VO}_{2 \max }$ of chemically synthesized drug addicts (A) and natural plant-derived drug addicts (B). Note: "a" in (A) represents the difference between the $\mathrm{VO}_{2 \max }$ measured by C PX and the $\mathrm{VO}_{2 \max }$ estimated by the years of drug use combined with the step index, and "b" means the mean value of the two. "c" in (B) represents the difference between the $\mathrm{VO}_{2 \text { max }}$ measured by $\mathrm{CPX}$ and the $\mathrm{VO}_{2 \text { max }}$ estimated by the step index, and "d" represents the mean value of the two.

estimating the $\mathrm{VO}_{2 \max }$ of chemically synthesized drug addicts, while the unary linear regression constructed with step index could more effectively and accurately estimate the $\mathrm{VO}_{2 \max }$ of natural plant-derived drug addicts. Previous studies have shown that the step test has good measurement reliability and could effectively assess the cardiovascular system functions of the body, and the step test index was more sensitive to exercise effects than $\mathrm{VO}_{2 \max }$ (Wang and Deng, 2003). Studies have shown that compared with riding power bikes, up and down steps can mobilize more muscles throughout the body, promote blood oxygen circulation, and increase oxygen consumption (Fan et al., 2019). However, simply relying on the step index to determine $\mathrm{VO}_{2 \max }$ was gradually being questioned. During the test, it was necessary to return to the physiology itself to better estimate $\mathrm{VO}_{2 \max }$ and other aerobic fitness (Ryhming, 1953). This may be because the exercise load conditions of the step test are constantly changing, and the step height, exercise rhythm and duration, and even the calculation method of the step index vary with different test subjects (Buckley et al., 2004). Based on this, many scholars have added the physiological and morphological characteristics of the subject in the process of predicting $\mathrm{VO}_{2 \max }$, hoping to improve the accuracy of predicting $\mathrm{VO}_{2 \max }$ (Wang et al., 2008). From the results, after we combined the years of drug use with the step index, the prediction accuracy of the $\mathrm{VO}_{2 \max }$ for chemically synthesized drug addicts was significantly improved, indicating that the appropriate combination of individual characteristics was, in fact, more conducive to improving the estimation accuracy. Therefore, the important variable of the years of drug use should be fully considered in this study (Jiang, 2006; Chen Y. L. et al., 2017). In natural plant-derived drug addicts, combining the years of drug use and the step index, the estimation accuracy was also better than the estimation accuracy of simple highleg lift and walking time. However, in comparison, using a single step index to estimate the $\mathrm{VO}_{2 \max }$ of natural plant-derived drug addicts has the highest accuracy. We speculated that this may be related to the influence of different drug types on the physiological characteristics of the addicts and the difference in the years of drug use.

However, since this study was the first to explore the method of estimating $\mathrm{VO}_{2 \max }$ of men drug addicts, there were some limitations. For example, the sample size of this study was relatively small, and the samples were all in Chongqing, China, which easily leads to the lack of universality of the study results. Meanwhile, based on the results of this study, we do not know whether the three estimation methods in this study were equally applicable to female drug addicts. In terms of estimation methods and techniques, in addition to the three methods used in this study, other more scientific and effective methods require followup study to discuss them in depth. In addition, future studies can also use more advanced science and technology (such as artificial intelligence, etc.) to improve estimation power.

\section{CONCLUSION}

Indirect measurement methods such as the 30-s raising legs, 1,000-m walking, and 3-min step experiment could effectively estimate the $\mathrm{VO}_{2 \max }$ of men drug addicts, but there were certain differences between the best estimation methods for chemically synthesized and natural plant-derived drug addicts. From the perspective of prediction accuracy, multiple linear regression constructed by the years of drug use combined with the step index has the highest estimated accuracy for the $\mathrm{VO}_{2 \max }$ of chemically synthesized drug addicts, while the unary regression equation established by a single step index has the highest estimated accuracy for the $\mathrm{VO}_{2 \max }$ of natural plant-derived addicts. Therefore, future studies can fully consider the physical characteristics of drug users and combine more cutting-edge science and technology to make the estimation accuracy of $\mathrm{VO}_{2 \max }$ closer to the real level. 


\section{DATA AVAILABILITY STATEMENT}

The original contributions presented in the study are included in the article/supplementary material, further inquiries can be directed to the corresponding author/s.

\section{ETHICS STATEMENT}

The studies involving human participants were reviewed and approved by Ethics Committee of Southwest University Hospital. The patients/participants provided their written informed consent to participate in this study.

\section{REFERENCES}

American College of Sports Medicine (2013). Resource Manual for Guidelines for Exercise Testing and Prescription, 9th ed. Philadelphia, PA: Lippincott William andWilkins.

Aspenes, S. T., Nilsen, T. I., Skaug, E. A., Bertheussen, G. F., Ellingsen, O., and Vatten, L., et al. (2011). Peak oxygen uptake and cardiovascular risk factors in 4631 healthy women and men. Med. Sci. Sports Exerc. 43, 1465-1473. doi: 10.1249/MSS.0b013e31820ca81c

Bosquet, L., Léger, L., and Legros, P. (2002). Methods to determine aerobic endurance. Sports Med. 32, 675-700. doi: 10.2165/00007256-200232110-00002

Buckley, J. P., Sim, J., Eston, R. G., Hession, R., and Fox, R. (2004). Reliability and validity of measures taken during the Chester step test to predict aerobic power and to prescribe aerobic exercise. Br. J. Sports Med. 38, 197-205. doi: 10.1136/bjsm.2003.005389

Calders, P., Deforche, B.,Verschelde, S., Bouckaert, J., Chevalier, F., and Bassle, E., et al. (2008). Predictors of 6-minute walk test and 12-minute walk/run test in obese children and adolescents. Eur. J. Pediatr. 167, 563-568. doi: 10.1007/s00431-007-0553-5

Chen, S. J., Liu, Z. Q., and Xu, L. J. (2017). Research progress on drug addiction and cognitive impairment. J. Pract. Med. 33, 324-327. doi: 10.3969/j.issn.1006-5725.2017.02.045

Chen, Y. L., Zhao, M. X., Zhang, J. X., Wang F. F., Wang W. X., Zhang Y., et al. (2017). Analysis of factors related to mental health and drug abuse of drug addicts in compulsory isolation during rehabilitation. Chin. J. Drug Depend. 26, 465-470. doi: 10.13936/j.cnki.cjdd1992.2017.06.012

Cooper, K. H. (1968). A means of assessing maximal oxygen intake correlation between field and treadmill testing. J. Am. Med. Assoc. 203:201. doi: 10.1001/jama.1968.03140030033008

Coquart, J., Tabben, M., Farooq, A., Tourny, C., and Eston, R. (2016). Submaximal, perceptually regulated exercise testing predicts maximal oxygen uptake: a meta-analysis study. Sports Med. 46, 885-897. doi: 10.1007/s40279-0150465-x

Dolezal, B. A., Chudzynski, J., Storer, T. W., Abrazado, M., Penate, J., and Mooney, L., et al. (2013). Eight weeks of exercise training improves fitness measures in methamphetamine-dependent individuals in residential treatment. J. Addict. Med. 7, 122-128. doi: 10.1097/ADM.0b013e318282475e

Dong, Y. N., Qin, F., Qu, C. Y., Han, Z. N., Xu, M. X., and Wang, Z. W. (2017). Current status and prospects of evaluation and application of maximal oxygen uptake. Chin. J. Sports Med. 36, 731-739. doi: 10.16038/j.1000-6710.2017.08.013

Fan, C. Q., Xu, K., Nie, M. J., Xu, W. F., and Wang, M. (2019). Evaluation of the cardiopulmonary endurance: cardiopulmonary exercise test versus 6-minute two-step test. Chin. J. Tissue Eng. Res. 23, 3686-3691.

Feng, J. P., Yan, Y., Xu, Y. L., Lu, J. F., Sun, B., and Feng, L. S. (2019). Progress in research of exercise intervention for drug detoxification. China Sport Sci. Technol. 55, 3-11. doi: 10.16470/j.csst.2 019626

Guo, H., Sun, J. Q., and Zhang, Y. M. (2016). Correlation of 6-minute stairs climbing and descending test with oxygen uptake. J. Chengdu Sport Univ. 42, 14-18. doi: 10.15942/j.jcsu.2016.03.003

\section{AUTHOR CONTRIBUTIONS}

All authors designed this study, contributed and approved the final manuscript. KW and $\mathrm{HJ}$ carried out the experiment procedure. XC recruited the individuals with drug addicts. LY and TZ undertook the statistical analysis and graphical representation of the data. JL revised the draft.

\section{FUNDING}

This study was supported by the Fundamental Research Funds for the Central Universities of China (Grant No. SWU2009103).

Guo, H. Y., An, P., and Yu, S. S. (2005). Analysis on the age characteristics of step test indexes and its influential factors. J. Beijing Univ. Phys. Educ. 5, 626-627. doi: 10.19582/j.cnki.11-3785/g8.2005.05.019

Han, Y. F. (2010). Compare of the Indirect Methods for Measuring Athletes' VO2max. Beijing Sport University. Available online at: https://kns.cnki.net/KCMS/detail/detail.aspx?dbcode=CMFD\&dbname=CMF D2010\&filename $=$ 2010123312.nh\&v=MDY5Nzk4ZVgxTHV4WVM3RGgxVD NxVHJXTTFGckNVUjd1ZllPZHFGQ3ZnVzd2T1YxMjZIcks2SGRMTnJaRW JQSVI=

Henry, B. L.,Minassian, A., and Perry, W. (2012). Effect of methamphetamine dependence on heart rate variability. Addict. Biol. 17, 648-658. doi: 10.1111/j.1369-1600.2010.00270.x

Hu, G. S. (1992). The harm of drug abuse. Bull. Biol. 5, 23-26.

Huang, F., Tan, J. X., Zheng, G. J., Ma, Z. F., Ma, J. Y., Pan, G. W., et al. (2010). Extensive central nervous system damage after drug withdrawal. Chin. J. Nerv. Mental Dis. 1, 42-43.

Jiang, T. (2006). Research on social support network for drug addicts: a survey of drug rehabilitation institutions in Nanan District of Chongqing. Chin. J. Sociol. $4,160-172$.

Katzmarzyk, P. T., Church, T. S., Janssen, I., Ross, R., and Blair, S. N. (2004). Cardiorespiratory fitness attenuates metabolic-associated mortality risk in normal weight, overweight, and obese men. Med. Sci. Sports Exerc. 36, S135S135. doi: 10.1249/00005768-200405001-00643

Kittredge, J. M., Rimmer, J. H., and Looney, M. A. (1994). Validation of the Rockport Fitness Walking Test for adults with mental retardation. Med. Sci. Sports Exerc. 26, 95-102. doi: 10.1249/00005768-199401000-00016

Larsen, C. M., Ball, C. A., Hebl, V. B., Geske, J. B., Ong, K. C., Siontis, K. C., et al. (2014). Echocardiographic predictors of cardiopulmonary exercise test performance in hypertrophic cardiomyopathy. Circulation 130, A17268A17268.

Li, J. J., Zhuang, J., Chen, P. J., and Jin, J. (2007). Study on correlation between step test and bicycle ergometer VO2max test. China Sport Sci. 27, 65-68. doi: $10.16469 /$ j.css.2007.05.010

Li, J. Y., Ren, J. J., and Cao, F. R. (2010). The correlation research between maximal oxygen uptake at maximal oxygen uptake platform and twelveminute run $1000 \mathrm{~m}$ run of male university students. J. Beijing Sport Univ. 33, 65-67. doi: 10.19582/j.cnki.11-3785/g8.2010.08.017

Li, Y. Z. (2001). An analysis on the causes, harmfulness and prevention to juvenile drug-addiction. J. Yunnan Public Security College 2, 45-48.

Lin, M., Liu, G. X., Lin, Y. P., Zhang, L. J., Zhang, L. J., and Xiong, Y. Q. (2018). Analysis of the status and influential factors of cardiopulmonary function in young office workers. Chin. General Pract. 21, 1568-1572. doi: 10.3969/j.issn.1007-9572.2018.13.012

Liu, A. H., and Dong, J. C. (2013). The application progress of cardiopulmonary exercise testing. Med. Recap. 19, 4125-4128. doi: 10.3969/j.issn.1006-2084.2013.22.032

National Anti-Drug Committee Office. (2019). 2018 China Drug Situation Report. Available online at: http://www.nncc626.com/2019-06/17/c_1210161797.htm

Ozburn, A. R., Janowsky, A. J., and Crabbe, J. C. (2015). Commonalities and distinctions among mechanisms of addiction to alcohol and other drugs. Alcohol Clin. Exp. Res. 39, 1863-1877. doi: 10.1111/acer.12810 
Panenka, W. J., Procyshyn, R. M., Lecomte, T., MacEwan, G. W., Flynn, S. W.,Honer, W. G., et al. (2013). Methamphetamine use: a comprehensive review of molecular, preclinical and clinical findings. Drug Alcohol Depend. 129, 167-179. doi: 10.1016/j.drugalcdep.2012.11.016

Paradisis, G. P., Zacharogiannis, E., Mandila, D., Smirtiotou, A., Argeitaki, P., and Cooke, C. B. (2014). Multi-Stage 20-m shuttle run fitness test, maximal oxygen uptake and velocity at maximal oxygen uptake. J. Hum. Kinet. 41, 81-87. doi: 10.2478/hukin-2014-0035

Ross, R. M., Murthy, J. N., Wollak, I. D., and Jackson, A. S. (2010). The six minute walk test accurately estimates mean peak oxygen uptake. BMC Pulm. Med. 223, 79-86. doi: 10.1186/1471-2466-10-31

Ryhming, I. (1953). A modified Harvard step test for the evaluation of physical fitness. Arbeitsphysiologie 15, 235-250. doi: 10.1007/BF00933320

Stogner, J. M., Sanders, A., and Miller, B. L. (2014). Deception for drugs: selfreported "doctor shopping" among young adults. J. Am. Board Fam. Med. 27, 583-593. doi: 10.3122/jabfm.2014.05.140107

van Holst, R. J., and Schilt, T. (2011). Drug-related decrease in neuropsychological functions of abstinent drug users. Curr. Drug Abuse Rev. 4, 42-56. doi: 10.2174/1874473711104010042

Wang, D. S., and Zhu, T. (2017). The impact of aerobic exercise on fitness, emotional state and craving among abstinent methamphetamine-dependent individuals. China Sport Sci. 37, 50-59. doi: 10.16469/j.css.201707007

Wang, J., and Deng, S. X. (2003). Inquiry on sidestep test. China Sport Sci. Technol. 39, 62-65. doi: 10.16470/j.csst.2003.02.021

Wang, K., Luo, J., Zhang, T. R., Ouyang, Y. Y., Zhou, C. L., and Lu, Y. Z. (2019). Effect of physical activity on drug craving of women with substance use disorder in compulsory isolation: mediating effect of internal inhibition. Front. Psychol. 10:928. doi: 10.3389/fpsyg.2019.01928

Wang, K., Zhang, T. R., Ouyang, Y. Y., Jiang, H. N., Qu, M. C., and Luo, J. (2020). An experimental study of step test index combined with heart rate variability in estimating maximum oxygen uptake in women with drug use disorder. Front. Physiol. 11:322. doi: 10.3389/fphys.2020.00322

Wang, N. H., Hong, P., and Su, Z. J. (2008). $\mathrm{VO}_{2 \max }$ estimation of male freshmen based on height, weight and vital capacity. Chin. J. Sports Med. 37, 202-207. doi: 10.16038/j.1000-6710.2018.03.005
Weisgerber, M., Danduran, M., Meurer, J., Hartmann, K., Berger, S., and Flores, G. (2009). Evaluation of cooper 12-minute walk/run test as a marker of cardiorespiratory fitness in young urban children with persistent asthma. Clin. J. Sport Med. 19, 300-305. doi: 10.1097/JSM.0b013e3181 b2077a

Xue, D. (2010). Drugs and their harm. Biol. Teach. 35,4-5.

Yang, Z. (2006). Drug harm. Observ. Ponderat. 2006, 18-21.

Ye, S. M. (1995). Drugs and their harm to personal psychology and physiology. Youth Explor. 5:9. doi: 10.13583/j.cnki.issn1004-3780.1995.05.003

Zarrabi, H., Khalkhali, M., Hamidi, A., Ahmadi, R., and Zavarmousavi, M. (2016). Clinical features, course and treatment of methamphetamineinduced psychosis in psychiatric inpatients. BMC Psychiatry 16:44. doi: 10.1186/s12888-016-0745-5

Zhu, J. H. (2000). The harm of drug abuse to the body. Chin. Pharm. Affairs 2000, 57-58. doi: 10.16153/j.1002-7777.2000. 05.031

Conflict of Interest: The authors declare that the research was conducted in the absence of any commercial or financial relationships that could be construed as a potential conflict of interest.

Publisher's Note: All claims expressed in this article are solely those of the authors and do not necessarily represent those of their affiliated organizations, or those of the publisher, the editors and the reviewers. Any product that may be evaluated in this article, or claim that may be made by its manufacturer, is not guaranteed or endorsed by the publisher.

Copyright (c) 2021 Wang, Jiang, Zhang, Yin, Chen and Luo. This is an open-access article distributed under the terms of the Creative Commons Attribution License (CC $B Y)$. The use, distribution or reproduction in other forums is permitted, provided the original author(s) and the copyright owner(s) are credited and that the original publication in this journal is cited, in accordance with accepted academic practice. No use, distribution or reproduction is permitted which does not comply with these terms. 